\title{
Radiation dose to the eyes of readers at the least distance of distinct vision from Nigerian daily newspapers
}

\author{
Akinloye M. K. ${ }^{1}$, Abodunrin O. P. ${ }^{2}$ \\ ${ }^{I}$ (Physics Department, Faculty of Pure and Applied Sciences/ LADOKE AKINTOLA UNIVERSITY OF \\ TECHNOLOGY, Nigeria) \\ ${ }^{2}$ (Physical Sciences Department, College of Natural and Applied Sciences/ BELLS UNIVERSITY OF \\ TECHNOLOGY, Nigeria)
}

\begin{abstract}
This work reports the measurements of the radionuclide contents in some widely read daily newspapers published in Nigeria, using gamma spectrometry. The radionuclides detected in the newspapers measured consisted of the natural radionuclides belonging to the series headed by ${ }^{228} \mathrm{Ra}$ and ${ }^{226} \mathrm{Ra}$ as well as the singly occurring radionuclide ${ }^{40} \mathrm{~K}$. The mean activity concentrations obtained for ${ }^{40} \mathrm{~K},{ }^{226} \mathrm{Ra}$ and ${ }^{228} \mathrm{Ra}$ respectively in the newspapers were $183.41 \pm 135.43,9.06 \pm 3.64$ and $6.11 \pm 1.36 \mathrm{Bqkg}^{-1}, 139.10 \pm 90.38,7.58 \pm 1.87$ and 5.29 $\pm 1.33 \mathrm{Bqkg}^{-1}$ and $152.10 \pm 114.32,9.62 \pm 1.40$ and $5.76 \pm 1.29 \mathrm{Bqkg}^{-1}$ respectively from $P_{1}, P_{2}$ and $P_{3}$. The doses to the eyes due to the measured activity concentrations in the newspaper samples were determined for a distance of $0.25 \mathrm{~m}$ (least distance of distinct vision) from the eyes. The annual effective doses to the eye resulting from the activities of the radionuclides identified with observed regularity in all the newspaper samples, obtained in this study are $0.012 \pm 0.010,0.010 \pm 0.009,0.010 \pm 0.009 \mu S v y^{-1}$ respectively for the newspapers. These values show that the doses to the lens of the eye from the Nigerian newspapers assessed in this work are very low compared to the annual dose limit of $15 \mathrm{mSv} \mathrm{y}^{-1}$.
\end{abstract}

Keywords: newspapers, radioactivity, least distance of distinct vision, effective dose, eyes

\section{INTRODUCTION}

Environmental radiation comes from the sky, the earth and the air we breathe and the sources can be categorized as natural or man-made. The natural radionuclides, such as ${ }^{40} \mathrm{~K},{ }^{228} \mathrm{Ra}$ and ${ }^{226} \mathrm{Ra}$, constitute the bulk of the radionuclides present in the earth's crust [1]. Gamma rays emitted by ${ }^{40} \mathrm{~K}$ and the members of the decay series of ${ }^{232} \mathrm{Th}$ and ${ }^{238} \mathrm{U}$ thus constitute the main source of external exposure to man.

This work is set to examine some Nigerian newspapers as single product in everyday circulation. Thousands of everyday products and materials containing radioactive materials are surfacing around the world. Common kitchen cheese graters, reclining chairs, bathroom tiles, women's handbags and tableware manufactured with contaminated metals have been identified, some after having been in circulation for a considerable period of time $[2,3,4,5,6]$. Others are fencing wire and fence posts, shovel blades, elevator buttons, airline parts and steel used in construction. While some include food, personal cosmetics, inclusive of soaps, shampoos, deodorants, toothpaste, mouthwash, body wash; furniture and bedsprings. Thousands of consumer goods and millions of grams of unfinished metal and its by-products have been found to contain low levels of radiation [7].

The effect of low-level ionizing radiation on the human population is considered to be a subject matter of contradictions; some researchers believe that all levels of ionizing radiations, no matter how low, are hazardous to health: whereas, the other says that an adaptive mechanism is formed within the human body due to a certain level of exposure below which the health effects on organisms are negligible [8]. This study is not intended to give any affirmation of either view. Succinct discussions on these are available in literatures. The divergence of opinion among stakeholders may impact whether health protection criteria expressed in terms of exposure to radioactive contamination, for instance as radiation dose or intakes of radionuclides, are acknowledged as representative of a particular level of protection expressed in terms of risk. Granted explicit consideration, we suggest that different views among stakeholders about such issues should be recognised. This study is set to quantify the level of radiation in one of the materials found in the environment, especially those in daily use so as to estimate the biological hazard that could be posed by them. A study of this sort will definitely add to our knowledge of radioactivity in materials around us, thereby increasing the available data.

Paper is the number one material that is thrown away. For every $100 \mathrm{~kg}$ of trash, $35 \mathrm{~kg}$ is paper [9]. Newspapers take up about 14 percent of landfill space, and paper used in packaging accounts for another 15 to 20 percent [9]. This shows how much of paper products are in daily use. Amidst other factors, the origin of the radiation hazard in newspapers may be the materials from which the newspapers are made [10]. Uptake of radionuclides in the environment by trees may be the source of radioactivity in the newspapers. Hence, the types of radioactivity in the newspapers depend on the environment of the place where the raw material is taken from. 
Newspapers may be considered, though at low level, as a contributor to radioactivity in libraries, offices, homes and other places where they may be stored. Various studies have been carried out on books produced from different parts of the world; while recording certain levels of natural and artificial radionuclides in books $[8,10,12,13]$, data on newspapers are seemingly scare if available at all.

The purpose of this study is to determine the radioactivity levels of some Nigerian Daily Newspapers, by taking precise measurements of their radionuclide contents and calculating the dose rate due to the activity of the radionuclides found in them. Hence this work will afford one of the preliminary information in the archive of environmental radiation. The data was used to investigate the level of radiological hazards due to exposure to these newspapers at the least distance of distinct vision for the eye (LDDV).

\section{MATERIALS AND METHODS}

The samples analysed in this study were newspapers from three different publishers, designated as $\mathrm{P}_{1}$, $\mathrm{P}_{2}$ and $\mathrm{P}_{3}$. These three dailies were chosen because they are the most preferred newspapers by the Nigerian populace. Several copies of the newspapers were collected directly from the respective publishers as well as from major vendors and some individuals. Future research may consider the effect of this sampling approach on the overall result. The papers were kept at room temperature; $27^{\circ} \mathrm{C}$ and relative humidity of about $70 \%$, for more than three months. The papers were then shredded into small sizes and packed into standard cylindrical plastic cans. Prior to packaging, the cans were thoroughly washed with dilute $\mathrm{HNO}_{3}(0.5 \mathrm{M})$ and rinsed with distilled water. This ensured dissolution of residual particles on the surface (internal and external) of the cans. Ten samples from each of the dailies were prepared, to make a total of thirty samples. The mass of each sample was carefully measured using a digital weighing balance $\left(\mathrm{ADAM}^{\mathrm{R}}\right.$ model) with $0.01 \mathrm{~g}$ accuracy. The cans were tightly sealed and kept in the laboratory for more than 28 days to ensure there was secular radioactive equilibrium. The samples were then analysed for radionuclide concentrations at the Gamma Laboratory of the Centre for Energy Research and Development, ObafemiAwolowo University, Ile-Ife.

The spectrometer consists of a high efficiency $\mathrm{NaI}(\mathrm{Tl}), 3 \mathrm{~m} 3 / 3$ Canberra model enclosed in a $100 \mathrm{~mm}$ thick lead shield, coupled to a versatile 2048-channel multichannel analyser (MCA) which uses S100 Canberra software. The detector was placed in the centre of the shield in order to minimize the effect of scattered radiations. The detector was calibrated to display photopeaks within the energy range of interest (60 to 2,000 $\mathrm{keV}$ ), using a mixed multi-nuclide standard source from IAEA, Vienna. The choice of gamma-ray peaks of the radionuclides used for measurements was made taking into account, the modest energy resolution of the $\mathrm{NaI}(\mathrm{Tl})$ detector used in the present study. The activity concentrations of ${ }^{228} \mathrm{Ra}$ and ${ }^{226} \mathrm{Ra}$ were determined indirectly from the gamma-rays emitted by their progenies: ${ }^{228} \mathrm{Ac}(911.07 \mathrm{keV}, 29.0 \%)$ and ${ }^{208} \mathrm{Tl}(583.19 \mathrm{keV}, 86.0 \%)$ for ${ }^{228} \mathrm{Ra},{ }^{214} \mathrm{Bi}(1764.49 \mathrm{keV}, 15.1 \%$; $1120.30 \mathrm{keV}, 15.7 \% ; 609.31 \mathrm{keV}, 46.1 \%)$ and ${ }^{214} \mathrm{~Pb}(351.92 \mathrm{keV}, 37.1 \%)$ for ${ }^{226} \mathrm{Ra}$ while that of ${ }^{40} \mathrm{~K}$ was determined by its gamma-line of $1460.75 \mathrm{keV}(10.5 \%)$. Each sample was placed on the detector and counted with a counting time of $36,000 \mathrm{~s}$. The background measurements were taken with an empty can of the same geometry as the samples for $36,000 \mathrm{~s}$ and the average subtracted from the spectrum of the sample. In plants, the radioactivity of ${ }^{232} \mathrm{Th}$ and ${ }^{238} \mathrm{U}$ are lesser than the radioactivity of ${ }^{228} \mathrm{Ra}$ and ${ }^{226} \mathrm{Ra}$ because plants absorb radium preferentially to thorium and uranium [10]. The activity $\mathrm{A}_{\mathrm{i}}$, for radionuclide $\mathrm{i}$, in each newspaper sample was determined using the relation:

$$
A_{i}=\frac{C_{i}}{\varepsilon \times I_{\gamma}}
$$

where $\mathrm{C}_{\mathrm{i}}$ is the net peak area in cps, $\varepsilon$ is the counting efficiency of the detector at energy $\mathrm{E}(\mathrm{keV})$ and $\mathrm{I}_{\gamma}$ is abundance of gamma emissions per radioactive decay.

\subsection{Estimation of Dose and Annual Effective Dose at LDDV}

The doses to the eyes due to the measured activity in the newspaper samples were calculated while making the following assumptions:

- That the newspaper was held at a distance of $0.25 \mathrm{~m}$ (LDDV) from the eyes.

- That the activity in newspaper was uniformly distributed in the material of the newspaper.

- That the newspaper was kept open for reading at approximately half the number of pages, e.g., at page 20 of a 40 page newspaper, to keep the source evenly distributed.

The dose, $\mathrm{D}\left(\mu \mathrm{Sv} \mathrm{h}^{-1}\right)$, to the eyes at LDDV from the source was calculated by using Equation 2 [8]: $D=4 \pi \varphi k_{\gamma} S_{A} \mu S v h^{-1}$

where $\varphi$ is a constant whose value corresponds to the surface area of the measuring can, $k_{\gamma}$ is the specific gamma ray constant and $S_{A}$ is the specific activity of newspaper (i.e. activity divided by surface area of the can) in $\mathrm{Bqm}^{-2}$. The values of $k_{\gamma}$ were calculated using Equation 3 [14].

$$
k_{\gamma}=0.5 \sum_{i} E_{i} f_{i} \frac{(C / \mathrm{kg}) \mathrm{m}^{-2}}{M B q \mathrm{~h}}
$$


where $E_{i}$ is the energy of the $i$ th radionuclide in $\mathrm{MeV}, f_{i}$ is the intensity of energy of interest. The annual effective dose, $\mathrm{H}_{\mathrm{E}}\left(\mu \mathrm{Sv} \mathrm{y}^{-1}\right)$, resulting from the three different newspapers assessed in this study were calculated using equation 4.

$$
H_{E}=D \times T
$$

where $\mathrm{D}$ is the calculated dose rate (in $\mu \mathrm{Sv} \mathrm{h}^{-1}$ ) and $\mathrm{T}$ is the total number of hours in a year. We did not however consider the intervening air between the eye and the newspaper.

\section{RESULTS AND DISCUSSION}

The mean values obtained from measurements of activity of the radionuclides found in the three newspapers are presented in Table 1. The activity concentrations obtained ranged from $23.46 \pm 2.14 \mathrm{Bqkg}^{-1}$ to $392.80 \pm 35.63 \mathrm{Bqkg}^{-1}, 3.85 \pm 0.23 \mathrm{Bqkg}^{-1}$ to $15.28 \pm 2.19 \mathrm{Bqkg}^{-1}$ and $3.71 \pm 0.21 \mathrm{Bqkg}^{-1}$ to $9.52 \pm 2.53 \mathrm{Bqkg}^{-1}$ in all the samples, with an average of $158.20 \pm 112.22 \mathrm{Bqkg}^{-1}, 8.75 \pm 2.56 \mathrm{Bqkg}^{-1}$ and $5.72 \pm 1.30 \mathrm{Bqkg}^{-1}$ for ${ }^{40} \mathrm{~K},{ }^{226} \mathrm{Ra}$ and ${ }^{228} \mathrm{Ra}$ respectively. Considering the mean activity obtained in this work for ${ }^{40} \mathrm{~K}$, ${ }^{226} \mathrm{Ra}$ and ${ }^{228} \mathrm{Ra}$, it is reasonable to conclude, as expected, that the dominant source of $\gamma$-radiation measured in all the newspaper samples was ${ }^{40} \mathrm{~K}$ (Figure 1).

As at the time of reporting this study, there are no data for radioactivity in newspapers produced in Nigeria and the world at large.

The radiation doses to the eye at the LDDV obtained from the activity of radionuclides found in each of the samples of the three newspapers assessed in this work are presented in Table 2. The dose levels obtained in all the samples using equation 2 , for ${ }^{40} \mathrm{~K},{ }^{226} \mathrm{Ra}$ and ${ }^{228} \mathrm{Ra}$ respectively varied from 0.08 to $1.06 \mathrm{pSv} \mathrm{h}^{-1}, 0.14$ to $0.59 \mathrm{pSv} \mathrm{h}^{-1}$ and 0.42 to $0.88 \mathrm{pSv} \mathrm{h}^{-1}$ in $\mathrm{P}_{1}, 0.15$ to $0.81 \mathrm{pSv} \mathrm{h}^{-1}, 0.15$ to $0.36 \mathrm{pSv} \mathrm{h}^{-1}$ and 0.35 to $0.63 \mathrm{pSv} \mathrm{h}^{-1}$ in $\mathrm{P}_{2}$ and 0.06 to $0.65 \mathrm{pSv} \mathrm{h}^{-1}, 0.21$ to $0.39 \mathrm{pSv} \mathrm{h}^{-1}$ and 0.26 to $0.56 \mathrm{pSv} \mathrm{h}^{-1}$ in $\mathrm{P}_{3}$. Approximate value of the total radiation dose from these three radionuclides is $1.32 \pm 0.10 \mathrm{pSv} \mathrm{h}^{-1}, 1.19 \pm 0.12 \mathrm{pSv} \mathrm{h}^{-1}$ and $1.16 \pm 0.09 \mathrm{pSv} \mathrm{h}^{-1}$ respectively from $P_{1}, P_{2}$ and $P_{3}$ newspaper. The highest dose rate occurred in $P_{1}$ newspaper, while $P_{3}$ newspaper recorded the lowest dose rate. The values obtained from this study show that the net activities of these natural radionuclides in the overall material (the pulp and the additives, and the equipment) used in the production of these newspapers are reasonably low when assessed at LDDV.

Using equation (4), the estimated annual effective dose value is $0.012 \pm 0.001 \mu \mathrm{Sv}^{-1}$ for $\mathrm{P}_{1}$ newspaper, $0.010 \pm 0.009 \mu \mathrm{Sv} \mathrm{y}{ }^{-1}$ for $\mathrm{P}_{2}$ newspaper and $0.010 \pm 0.009 \mu \mathrm{Sv} \mathrm{y}^{-1}$ for $\mathrm{P}_{3}$ newspaper (Figure 2). The estimated value obtained for $\mathrm{P}_{2}$ and $\mathrm{P}_{3}$ are the same, while $\mathrm{P}_{1}$ recorded the highest value. People who spend long hours reading newspaper $\mathrm{P}_{1}$ are likely to accumulate more doses of radiation than those with $\mathrm{P}_{2}$ and $\mathrm{P}_{3}$ (Figure 2). However, these results are obviously much lower than the annual dose limit of $15 \mathrm{mSv} \mathrm{y}^{-1}$ to the lens of the eye as recommended by the ICRP [15] (1991). In view of this it is reasonable to state that the doses resulting from the radionuclides contained in the newspapers analysed in this study may not result in significant exposure to the eyes of the readers at LDDV.

\section{CONCLUSION}

The measurements of the radionuclide contents of some Nigerian Daily Newspapers have been carried out using gamma-ray spectrometry system in this work. The mean activity concentrations obtained in this work showed that the dominant source of $\gamma$-radiation measured in all the newspaper samples was ${ }^{40} \mathrm{~K}$. The doses resulting from the activity of the radionuclides obtained in the newspapers at $0.25 \mathrm{~m}$, which is the least distance of distinct vision for the eye, were determined.

The annual effective dose values of $0.012 \pm 0.001 \mu \mathrm{Sv} \mathrm{y}^{-1}$ for $\mathrm{P}_{1}$ newspaper, $0.010 \pm 0.009 \mu \mathrm{Sv} \mathrm{y}^{-1}$ for $\mathrm{P}_{2}$ newspaper and $0.010 \pm 0.009 \mu \mathrm{Sv} \mathrm{y}^{-1}$ for $\mathrm{P}_{3}$ newspaper obtained from the present study are much lower than the annual dose limit of $15 \mathrm{mSv} \mathrm{y}^{-1}$ to the lens of the eye. Hence the radiological hazard from these newspapers can be considered to be negligible.

In the subsequent study, a more representative sampling approach will be employed. Also needful to be determined is the effect of the intervening air on the result obtainable at such a distance to the eye of the readers.

\section{REFERENCES}

[1] UNSCEAR. United Nations Scientific Committee on the Effects of Atomic Radiation, Sources and effects of ionizing radiation: Report to the General Assembly, with Scientific Annexes. United Nations, New York. 1993.

[2] NCRP. National Council on Radiation Protection and Measurements: Exposure of the population in the United States and Canada from background radiation, NCRP Report No. 94, Bethesda MD 20814, 1987.

[3] A.D.Golnick, Basic radiation technology(Altadena, CA:Pacific Radiation Corporation, $3^{\text {rd }}$ Edition, 1994).

[4] G.J.Couch, L.K.Vaughn, Radioactive consumer products in the classroom,The Physics Teacher, 33, 1995, 18-22.

[5] M,Yahong,L,Yigang,Z,Guang,and H,Xiaolei, The studies on radiological limits of color - glazed tiles used in home decoration,Health Physics, 82(4), 2002, 510-512.

[6] S,Verità,S,Righi,R,Guerra,and M,Jeyapandian, Radon exhalation rates from Zircon sands and ceramic tiles in Italy,Radioprotection 44(5), 2009, 445-451. 
[7] EC. European Commission Radiation Protection 146. A review of consumer products containing radioactive substances in the European Unionfinal report of the study contract for the European Commission B4-3040/2001/327150/MAR/C4. 2007.

[8] M.A. Imtiaz,B,Aleya,A.S. Mollah, and M.A.Zaman,Measurements of radioactivity in books and calculations of resultant eye doses to readers,Health Physics, 88(2), 2005, 169-174.

[9] NEEDP. National Energy Education Development Project: Museum of solid waste, 2006, $10-64$.

[10] A, Kobashi, Radioactivity in books printed in Japan: its source and relation to the year of issue, Journal of Radiation Research,37, 1996, 81-95.

[11] K. Teschke, and P. Demers, Paper and pulp industry,in M.S. Jeanne (fourth edition),Encyclopedia of occupational health and safety, 3 (Geneva: International Labour Office,1998) 72.1-72.19.

[12] B.Y.Lalit, V.K.Shukla, and T.V.Ramachandran, Radioactivity content of books,Health Physics, 40, 1981, 731-735.

[13] B.Y.Lalit, and V.K.Shukla, Radioactivity in books produced during the last 50 years. Health Physics, 47, 1984, 447-451.

[14] H. Cember,and J.T.Edward, Introduction to Health Physics, (New York McGraw-Hill: Health Professional Division, 2008.

[15] ICRP. International Commission on Radiological Protection. 1990 - 1991 recommendations of the ICRP, New York: Pergamon Press. Publication 60. 1991, 21(1-3).

Table 1: Radionuclide Concentrations $\left(B q k g^{-1}\right)$ in the Newspaper Samples Analysed

$$
{ }^{40} \mathrm{~K} \quad{ }^{226} \mathrm{Ra} \quad{ }^{228} \mathrm{Ra}
$$

\begin{tabular}{llccc}
\hline $\mathbf{P}_{\mathbf{1}}$ & Range & $35.41 \pm 5.32-392.80 \pm 35.63$ & $3.85 \pm 0.23-15.28 \pm 2.19$ & $4.90 \pm 1.58-9.52 \pm 2.53$ \\
& Mean & $183.41 \pm 135.43$ & $9.06 \pm 3.64$ & $6.11 \pm 1.36$ \\
$\mathbf{P}_{\mathbf{2}}$ & Range & $54.18 \pm 7.64-333.90 \pm 30.25$ & $4.33 \pm 1.44-10.44 \pm 2.51$ & $3.77 \pm 0.11-7.60 \pm 3.20$ \\
& Mean & $139.10 \pm 90.38$ & $7.58 \pm 1.868$ & $5.29 \pm 1.33$ \\
$\mathbf{P}_{\mathbf{3}}$ & Range & $23.46 \pm 2.14-324.12 \pm 30.19$ & $7.37 \pm 2.51-12.70 \pm 2.14$ & $3.71 \pm 0.21-7.98 \pm 3.08$ \\
& Mean & $152.10 \pm 114.33$ & $9.62 \pm 1.40$ & $5.79 \pm 1.29$ \\
\hline
\end{tabular}

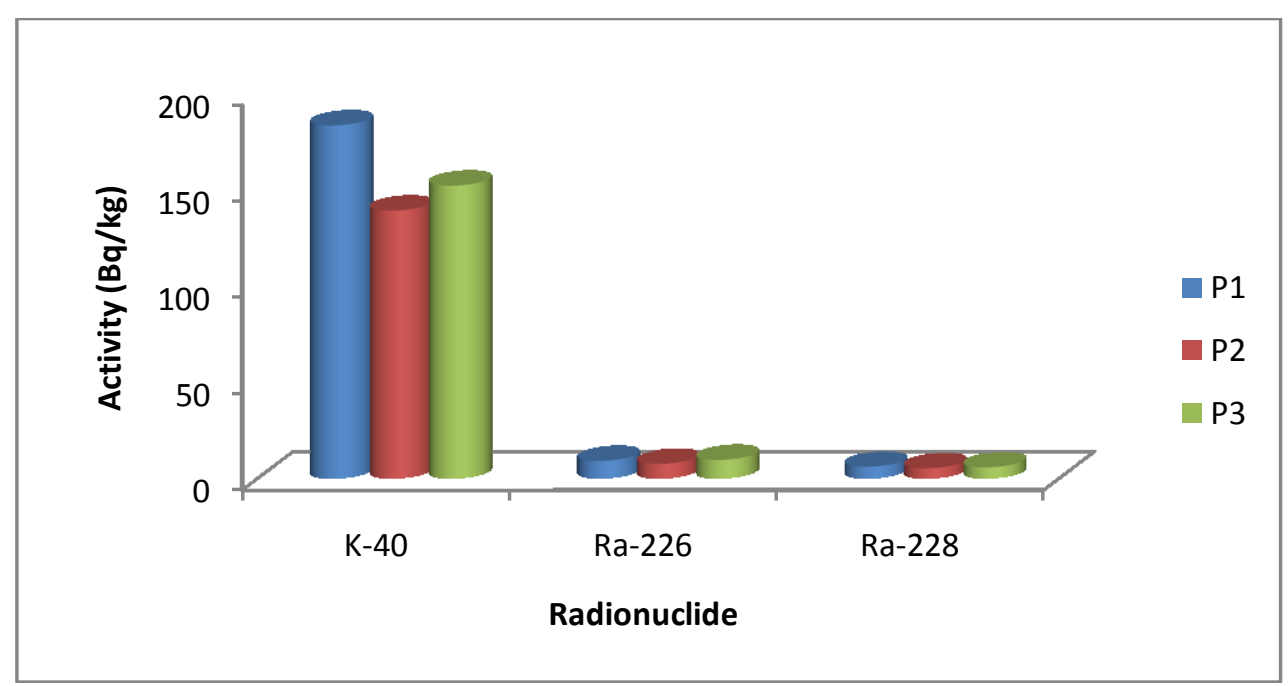

Figure 1: Radionuclide Concentrations in $\mathrm{P}_{1}, \mathrm{P}_{2}$ and $\mathrm{P}_{3}$ Newspapers

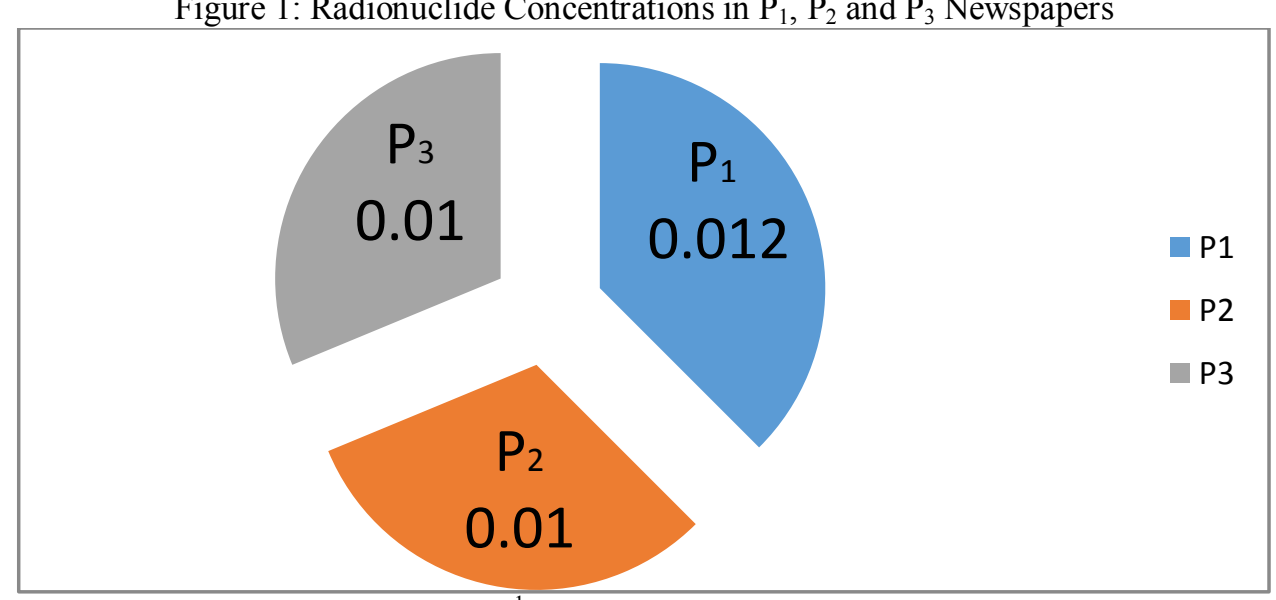

Figure 2: Annual Effective Dose $\left(\mu \mathrm{Sv}^{-1}\right)$ to the eye of the reader at least distance of distinct vision 
Table 2: Radiation Dose to the Eye of Readers $\left(S \vee h^{-1} \times 10^{-11}\right)$

\begin{tabular}{|c|c|c|c|}
\hline Sample & ${ }^{40} \mathrm{~K}$ & ${ }^{226} \mathrm{Ra}$ & ${ }^{228} \mathrm{Ra}$ \\
\hline$\overline{P_{1-1}}$ & 1.0548 & 0.3370 & 0.5566 \\
\hline 2 & 0.1457 & 0.2055 & 0.4234 \\
\hline 3 & 0.5763 & 0.2853 & 0.4516 \\
\hline 4 & 0.2770 & 0.3794 & 0.4263 \\
\hline 5 & 0.2485 & 0.4769 & 0.5902 \\
\hline 6 & 0.5844 & 0.5845 & 0.8746 \\
\hline 7 & 0.9606 & 0.3139 & 0.4950 \\
\hline 8 & 0.4845 & 0.4132 & 0.4513 \\
\hline 9 & 0.1976 & 0.1394 & 0.4887 \\
\hline 10 & 0.0820 & 0.1547 & 0.5432 \\
\hline Mean & 0.4611 & 0.3290 & 0.5301 \\
\hline$P_{2}-1$ & 0.2928 & 0.2540 & 0.4638 \\
\hline 2 & 0.6417 & 0.2110 & BDL \\
\hline 3 & 0.8125 & 0.1513 & 0.3473 \\
\hline 4 & 0.4718 & 0.3392 & 0.5687 \\
\hline 5 & 0.2893 & 0.2780 & 0.5906 \\
\hline 6 & BDL & 0.3068 & 0.5215 \\
\hline 7 & 0.1517 & 0.2167 & 0.3639 \\
\hline 8 & 0.4307 & 0.2784 & 0.6139 \\
\hline 9 & 0.3214 & 0.3619 & 0.6326 \\
\hline 10 & BDL & 0.2704 & 0.3914 \\
\hline Mean & 0.3412 & 0.2668 & 0.4494 \\
\hline$P_{3}-1$ & 0.5068 & 0.2593 & 0.4727 \\
\hline 2 & 0.1104 & 0.3091 & 0.5569 \\
\hline 3 & BDL & 0.3154 & 0.4659 \\
\hline 4 & 0.3899 & 0.2989 & 0.5751 \\
\hline 5 & 0.2770 & 0.3794 & 0.4297 \\
\hline 6 & BDL & 0.3078 & 0.5238 \\
\hline 7 & 0.0595 & 0.3862 & 0.4882 \\
\hline 8 & 0.6035 & 0.2427 & 0.5123 \\
\hline 9 & 0.6417 & 0.2130 & BDL \\
\hline 10 & 0.5068 & 0.2651 & 0.2593 \\
\hline Mean & 0.3096 & $\mathbf{0 . 2 9 7 7}$ & 0.4284 \\
\hline
\end{tabular}

